\title{
Implementation of a Single Phase Switched-Capacitor Nine-Level Inverter for PV System Applications with Selective Harmonic Elimination
}

\author{
Ayoub Nouaiti, Abdallah Saad, Abdelouahed Mesbahi, Mohamed Khafallah \\ Laboratory of Energy and Electrical Systems (LESE) \\ Superior National School of Electricity and Mechanical (ENSEM) \\ Hassan II University of Casablanca, B.P 8118, Oasis, Casablanca, Maroc
}

\begin{abstract}
The main objective of this paper is to present a test a single phase switched capacitor nine-level inverter for PV system applications, with a simple harmonic elimination method. The main elements of the used multilevel inverter are a high power switched capacitor DC-DC converter and a high power DC-AC converter. The studied system with the proposed control method was tested on MATLAB/SIMULINK with solar panels. Also, an experimental test bench was prepared and used to validate the simulation results. The all obtained results prove the high efficiency of the studied PV system with the implemented control method.
\end{abstract}

\section{Keywords}

$\mathrm{PV}$, Multilevel inverter, Switched capacitor converter, THD, Induction motor.

\section{INTRODUCTION}

Nowadays, the use of the renewable energy sources became very important in all the worldwide, because they offer good solutions to surmount pollution by decreasing the use of fossil sources [1]. For producing electricity, the most used renewable energy sources are solar energy and wind energy. In the case of the photovoltaic systems, it's necessary to use high-efficiency inverters for converting DC power energy produced from solar panels to AC power energy, in order to be used in the industrial criteria [2].

The classical two-level inverters, introduce many problems into the photovoltaic energy conversion chain, such as switching losses across the power switches and a lot of harmonics into the AC output voltages and currents; which will affect the performance of the electrical machines driven by theses AC parameters [3]. Multilevel inverters appear as an alternative solution to decrease electrical problems when converting energy in the photovoltaic systems because they deliver AC voltages with fewer harmonics, they reduce the size of filters and sometimes they eliminate them, they reduce switching losses of power switches by utilizing a part of the total DC voltage from solar panels, they decrease electromagnetic interference (EMI) problems, and the important thing is that they increase the efficiency of the photovoltaic energy conversion chain [3], [4], [5]. The most used multilevel inverter structures are; neutral point clamped inverter, Flying Capacitor Inverter, and cascaded H-Bridge Inverter [6]. In some cases, these structures pose some problems such as; unbalanced voltages across capacitors and the need of using several separate DC voltages sources as input voltages. The switched capacitors inverters can overcome some of these problems; for that, many topologies has been presented in the literature [7], [8], [9], [10], but generally, they are used just for the systems that operate with high frequency and can't be used with loads working under $50 \mathrm{~Hz}$ or $60 \mathrm{~Hz}$.

This paper presents a test of an inverter with nine levels for PV system applications, with a simple control technique based on selective harmonic elimination. This multilevel inverter consists of a switched capacitor DC-DC converter obtained from a new topology presented recently in the literature. This derived structure is tied with a full-bridge DC-AC converter. The studied multilevel inverter is tested with inductive load working under $220 \mathrm{~V}$ RMS and $50 \mathrm{~Hz}$ in simulation and also experimentally.

In this paper, section 2 presents the studied system, section 3 presents the selective harmonic elimination method, section 4 presents the simulation results, section 5 presents the experimental results and the final section presents the conclusion.

\section{DESCRIPTION OF THE STUDIED SYSTEM}

Figure 1 shows the topology of the studied photovoltaic system. It consists of a DC voltage source from solar panels (Vin), a switched capacitor DC-DC converter, a full bridge DC-AC converter, and a single-phase load.

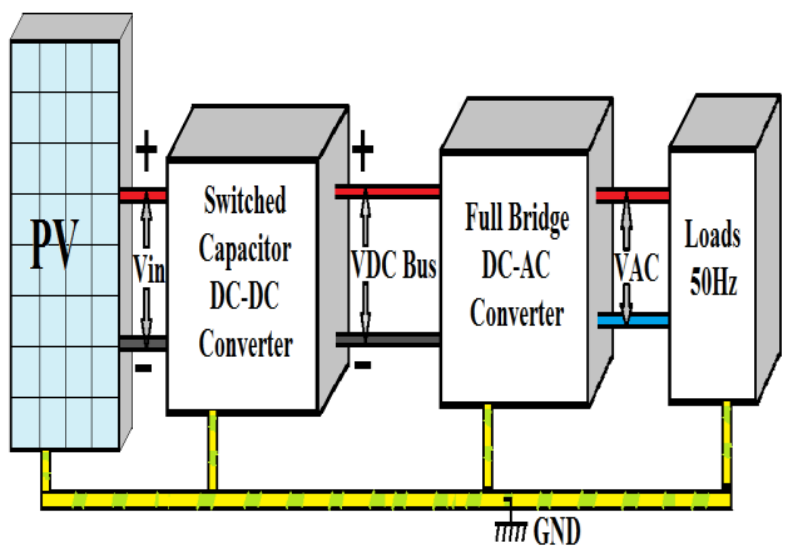

Fig 1.Topology of the studied system

\subsection{Solar panels}

Solar panels contain small solar cells made from several materials such as mono-crystalline silicon and polycrystalline silicon. They generate direct current (DC) through the photovoltaic effect by absorbing photons from the sunlight. 
Figure 2 shows a simple model of a solar cell composed of current source, single diode, parallel resistance and a series resistance.

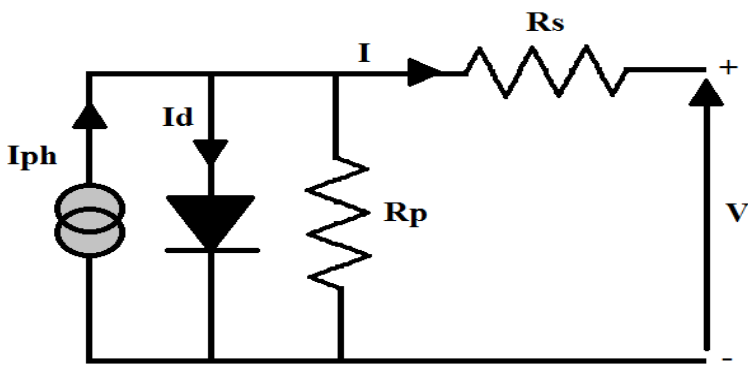

Fig 2.Simple model of a solar cell

The expression of the output current from this model is given in equation 1 [11], [12]:

$$
\mathrm{I}=\mathrm{Iph}-\mathrm{Is}\left(\exp \frac{\mathrm{q}(\mathrm{V}+\mathrm{RsI})}{\mathrm{NKT}}-1\right)-\frac{(\mathrm{V}+\mathrm{RsI})}{\mathrm{Rp}}
$$

Iph is the photocurrent, I is the output current, Is is the reverse saturation current of the diode, $\mathrm{V}$ is the output voltage, $\mathrm{N}$ is the ideality factor of the diode, $\mathrm{q}$ is the electron charge (1.60217662 $\times 10-19$ coulombs), $\mathrm{K}$ is the Boltzmann constant $(1.38064852 \times 10-23 \mathrm{~m} 2 \mathrm{~kg} \mathrm{~s}-2 \mathrm{~K}-1)$, and $\mathrm{T}$ is the junction temperature.

\subsection{Switched capacitor converter}

Figure 3 shows the used switched capacitor converter, which is obtained from a generalized structure, presented in [13], [14]. This DC-DC converter is composed of one DC voltage source (Vin), 3 diodes, 3 capacitors and 8 switches (power MOSFET). It's able to deliver an output voltage (VDC-Bus) four times greater than the input voltage.

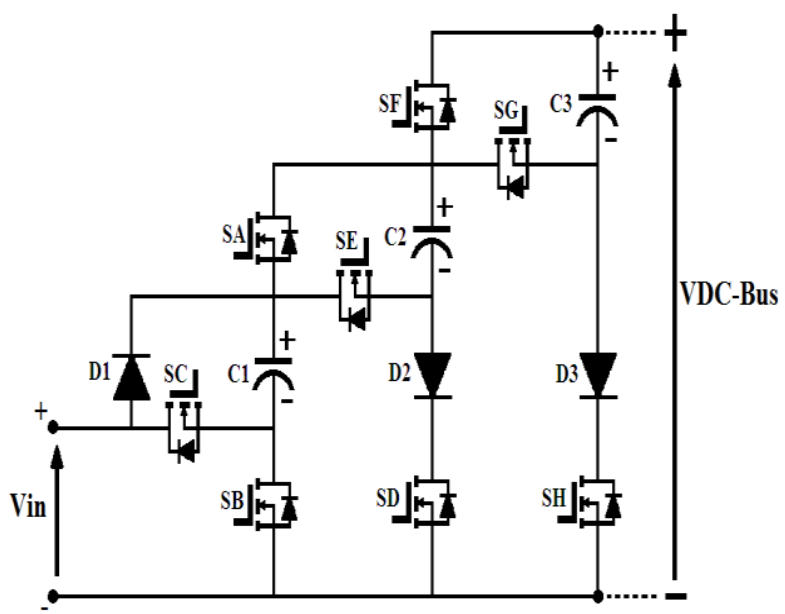

Fig 3.The switched capacitor converter

The operation of this converter can be divided into four modes.

Mode 1: the switches $\mathrm{SA}, \mathrm{SB}$, and $\mathrm{SF}$ are $\mathrm{ON}$; the remaining switches (SC, SD, SE, SG, and SH) are OFF. The diode D1 is forward biased; the remaining diodes are reversely biased. In this mode, the capacitor $\mathrm{C} 1$ is charged by Vin. The expression of the output DC Bus voltage is:

VDC Bus $=$ VC1 $=$ Vin
Mode 2: the switches SA, SC, SD, and SF are ON; the remaining switches (SB, SE, SG, and $\mathrm{SH}$ ) are OFF. The diode D2 is forward biased; the remaining diodes are reversely biased. In this mode, the capacitor $\mathrm{C} 2$ is charged by Vin and voltage across the capacitor $\mathrm{C} 1$ ( $\mathrm{VC} 1)$. By considering the value of $\mathrm{VC} 1$ from Equation 2, the new expression of the output DC Bus voltage is:

$\mathrm{VDC}$ Bus $=\mathrm{VC} 2=\mathrm{Vin}+\mathrm{VC} 1=2 \times$ Vin

Mode 3: the switches SE, SF, and $\mathrm{SH}$ are $\mathrm{ON}$; the remaining switches (SA, SB, SC, SD, and SG) are OFF. The diodes D1 and D3 are forward biased; the remaining diode is reversely biased. In this mode, the capacitor $\mathrm{C} 3$ is charged by Vin and voltage across the capacitor $\mathrm{C} 2$ ( $\mathrm{VC} 2$ ). By considering the value of $\mathrm{VC} 2$ from Equation 3, the new expression of the output DC Bus voltage is:

$\mathrm{VDC}$ Bus $=\mathrm{VC} 3=\mathrm{Vin}+\mathrm{VC} 2=3 \times \mathrm{Vin}$

Mode 4: the switches SA and SG are ON; the remaining switches (SB, SC, SD, SE, SF and SH) are OFF. The diode D1 is forward biased; the remaining diodes are reversely biased. By considering the value of VC3 from Equation 4, the new expression of the output DC Bus voltage is:

$\mathrm{VDC}$ Bus $=\mathrm{Vin}+\mathrm{VC} 3=4 \times \mathrm{Vin}$

It's clear from the different operation modes and from the developed equations (2-5), that the used converter can increase the input DC voltage just by switching the capacitors in series and in parallel, and without using high-frequency transformers or inductors.

\subsection{Full bridge dc-ac converter}

Figure 4 shows the used full-bridge DC-AC converter. It's composed of four switches (power MOSFET). It's tied to the used switched capacitor converter, in order to convert the output DC Bus voltage to an AC voltage with a specific frequency $(50 \mathrm{~Hz}$ in our case).

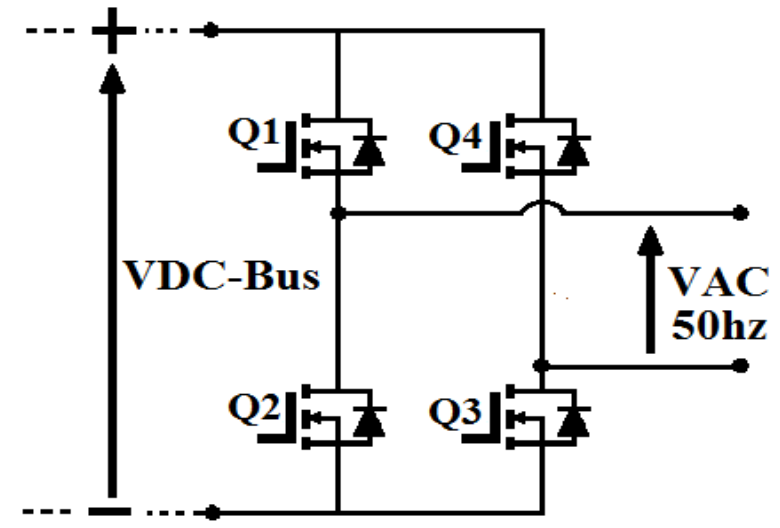

Fig 4.The DC-AC full bridge converter

\subsection{Switching states of the switches}

Table 1 shows the proposed switching states of the used switches (power MOSFET) with the associated voltages levels of the studied photovoltaic multilevel inverter.

From the proposed states, the studied multilevel inverter generates an output $\mathrm{AC}$ voltage with nine levels, as shown in Figure 5. 
Table 1.The proposed switching states of the switches

\begin{tabular}{|c|c|c|c|c|c|c|c|c|c|c|c|c|}
\hline \multicolumn{12}{|c|}{ SWITCHES STATES } & \multirow[b]{2}{*}{ VAC } \\
\hline Q1 & Q3 & Q4 & $\mathbf{Q 2}$ & SA & SB & $\mathrm{SC}$ & SD & $\mathbf{S E}$ & $\mathbf{S F}$ & SG & SH & \\
\hline $\mathrm{ON}$ & ON & OFF & OFF & ON & OFF & OFF & OFF & OFF & OFF & ON & OFF & $+4 \mathrm{Vin}$ \\
\hline $\mathrm{ON}$ & $\mathrm{ON}$ & OFF & OFF & OFF & OFF & OFF & OFF & $\mathrm{ON}$ & ON & OFF & ON & +3 Vin \\
\hline $\mathrm{ON}$ & $\mathrm{ON}$ & OFF & OFF & $\mathrm{ON}$ & OFF & $\mathrm{ON}$ & $\mathrm{ON}$ & OFF & $\mathrm{ON}$ & OFF & OFF & $+2 \mathrm{Vin}$ \\
\hline $\mathrm{ON}$ & $\mathrm{ON}$ & OFF & OFF & $\mathrm{ON}$ & $\mathrm{ON}$ & OFF & OFF & OFF & ON & OFF & OFF & + Vin \\
\hline $\mathrm{ON}$ & OFF & ON & OFF & $\mathrm{ON}$ & $\mathrm{ON}$ & OFF & OFF & OFF & ON & OFF & OFF & $\mathbf{0}$ \\
\hline OFF & $\mathrm{ON}$ & OFF & ON & $\mathrm{ON}$ & $\mathrm{ON}$ & OFF & OFF & OFF & ON & OFF & OFF & \\
\hline OFF & OFF & ON & ON & $\mathrm{ON}$ & $\mathrm{ON}$ & OFF & OFF & OFF & ON & OFF & OFF & -Vin \\
\hline OFF & OFF & ON & ON & ON & OFF & $\mathrm{ON}$ & $\mathrm{ON}$ & OFF & ON & OFF & OFF & -2 Vin \\
\hline OFF & OFF & ON & ON & OFF & OFF & OFF & OFF & $\mathrm{ON}$ & ON & OFF & ON & -3Vin \\
\hline OFF & OFF & ON & ON & ON & OFF & OFF & OFF & OFF & OFF & ON & OFF & +4Vin \\
\hline
\end{tabular}

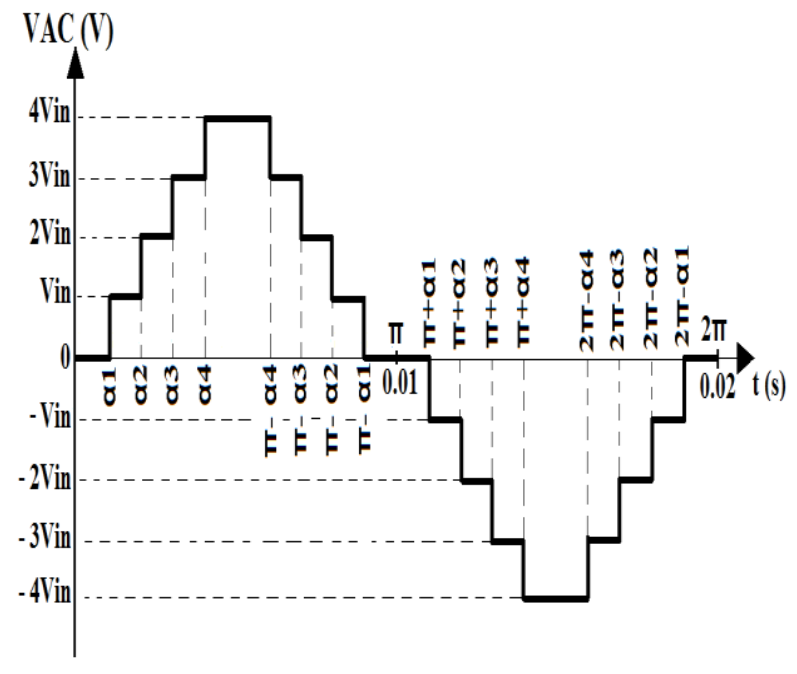

Fig 5.Output AC voltage waveform

\section{SELECTIVE HARMONIC METHOD}

The Fourier series expression of the studied multilevel inverter output voltage waveform (Figure 5) is developed in equation 6 [15]:

$\operatorname{VAC}(\omega \mathrm{t})=\mathrm{a}_{0}+\sum_{\mathrm{n}=1}^{\infty}\left(\left(\mathrm{a}_{\mathrm{n}} \cos (\mathrm{n} \omega \mathrm{t})\right)+\left(\mathrm{b}_{\mathrm{n}} \sin (\mathrm{n} \omega \mathrm{t})\right)\right)$

The output AC waveform is composed just of sinus terms. The quarter-wave of this $\mathrm{AC}$ voltage is symmetrical along the $\mathrm{x}$-axis; for that the even harmonics will be absent, $\mathrm{a} 0$ and an will be equal to zero, and the equation 6 will change to:

$\operatorname{VAC}(\omega \mathrm{t})=\sum_{\mathrm{n}=\mathrm{odd}}^{\infty} \mathrm{b}_{\mathrm{n}} \sin (\mathrm{n} \omega \mathrm{t})$

From equation 7, the simplified expression of the Fourier series expansion of the output $\mathrm{AC}$ waveform will be:

$\operatorname{VAC}(\omega \mathrm{t})=\frac{4 \operatorname{Vin}}{\mathrm{n} \pi} \sum_{\mathrm{n}=\mathrm{odd}}^{\infty}(\cos (\mathrm{n} \alpha 1)+\cos (\mathrm{n} \alpha 2)+$

$\cos (n \alpha 3)+\cos (n \alpha 4)) \sin (n \omega t)$

From the equation 8 , the expression of the fundamental voltage $\mathrm{V} 1$ of the output $\mathrm{AC}$ voltage is:

$\mathrm{b} 1=\frac{4 \mathrm{Vin}}{\pi}(\cos (\alpha 1)+\cos (\alpha 2)+\cos (\alpha 3)+\cos (\alpha 4)=\mathrm{V} 1$
The expression of the modulation index $\mathrm{M}$ which will control the studied multilevel inverter is given by equation 10 [15]:

$\mathrm{M}=\frac{\pi \times \mathrm{V} 1}{2 \times \mathrm{S} \times \mathrm{Vin}}(0 \leq \mathrm{M} \leq 1)$

In the positive quarter wave of the AC voltage (Figure 5), there are four steps for that; $\mathrm{S}$ will be equal to 4

In this paper, the objective is to get nine levels output AC voltage similar to a sinusoidal in shape with fewer harmonic for that; to eliminate the 3rd, 5th, 7th, and 9th order harmonics, the values of the switching angles seen in Figure 5 can be obtained by solving numerically the following equations derived from equations 8,9 and 10 with MATLAB program.

$\left\{\begin{array}{l}\cos (\alpha 1)+\cos (\alpha 2)+\cos (\alpha 3)+\cos (\alpha 4)=2 \times \mathrm{M} \\ \cos (3 \alpha 1)+\cos (3 \alpha 2)+\cos (3 \alpha 3)+\cos (3 \alpha 4)=0 \\ \cos (5 \alpha 1)+\cos (5 \alpha 2)+\cos (5 \alpha 3)+\cos (5 \alpha 4)=0 \\ \cos (7 \alpha 1)+\cos (7 \alpha 2)+\cos (7 \alpha 3)+\cos (7 \alpha 4)=0\end{array}\right.$

\section{SIMULATION RESULTS}

The studied multilevel inverter has been tested on MATLAB/SIMULINK by using four identical solar panels coupled in series as a DC source modeled with the use of equation1.

Table 2 shows the electrical parameters of one of the used solar panels.

Table 2.Electrical parameters of one solar panel

\begin{tabular}{|c|c|}
\hline Maximum power (Pmax) & $60 \mathrm{~W}$ \\
\hline Voltage at Pmax (Vmp) & $17.1 \mathrm{~V}$ \\
\hline Current at Pmax (Imp) & $3.5 \mathrm{~A}$ \\
\hline Short-circuit current (Isc) & $3.8 \mathrm{~A}$ \\
\hline Open-circuit voltage (Voc) & $21.1 \mathrm{~V}$ \\
\hline Number of solar cells & 36 \\
\hline
\end{tabular}

Figure 6 and Figure 7 show The I-V characteristics and P-V characteristics obtained from the model of one solar panel under different irradiation levels and temperatures levels. 


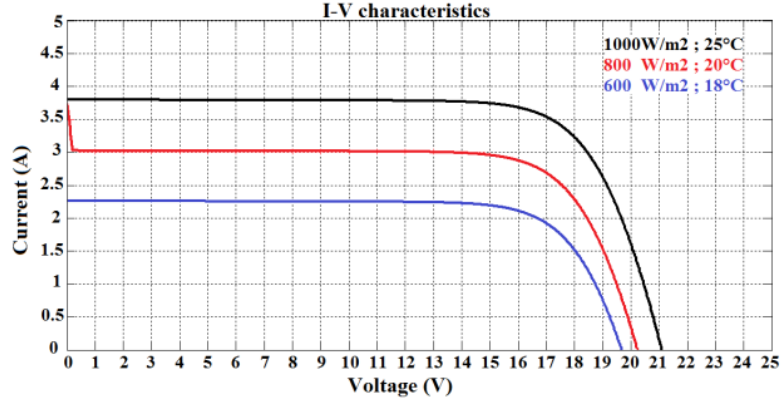

Fig 6.The I-V characteristics

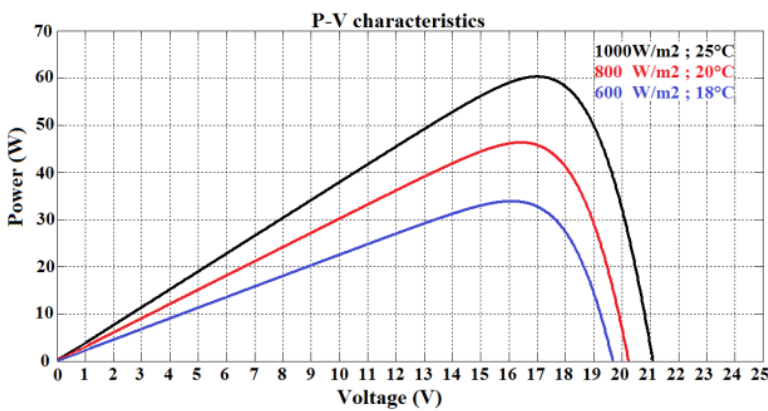

Fig 7.The P-V characteristics

In this simulation test, the irradiation level was fixed at $1000 \mathrm{~W} / \mathrm{m}^{2}$ and the temperature was fixed at $25^{\circ} \mathrm{C}$ for that; the maximum power across the four solar panels coupled in series is $4 \times 60=240 \mathrm{~W}$, and the total Voc voltage is $4 \times 21.1=84.4 \mathrm{~V}$.

In order to test the studied multilevel inverter in critical conditions, the studied PV system was simulated with an inductive charge with a small power factor $(\mathrm{R}=36.6 \Omega$; $\mathrm{L}=0.28 \mathrm{H}$; $\operatorname{Cos} \varphi=0.389$ ), and the selective harmonics control method was implemented with a modulation index of $\mathrm{M}=1.05$.

Figure 8 shows the SIMULINK model of the studied system.

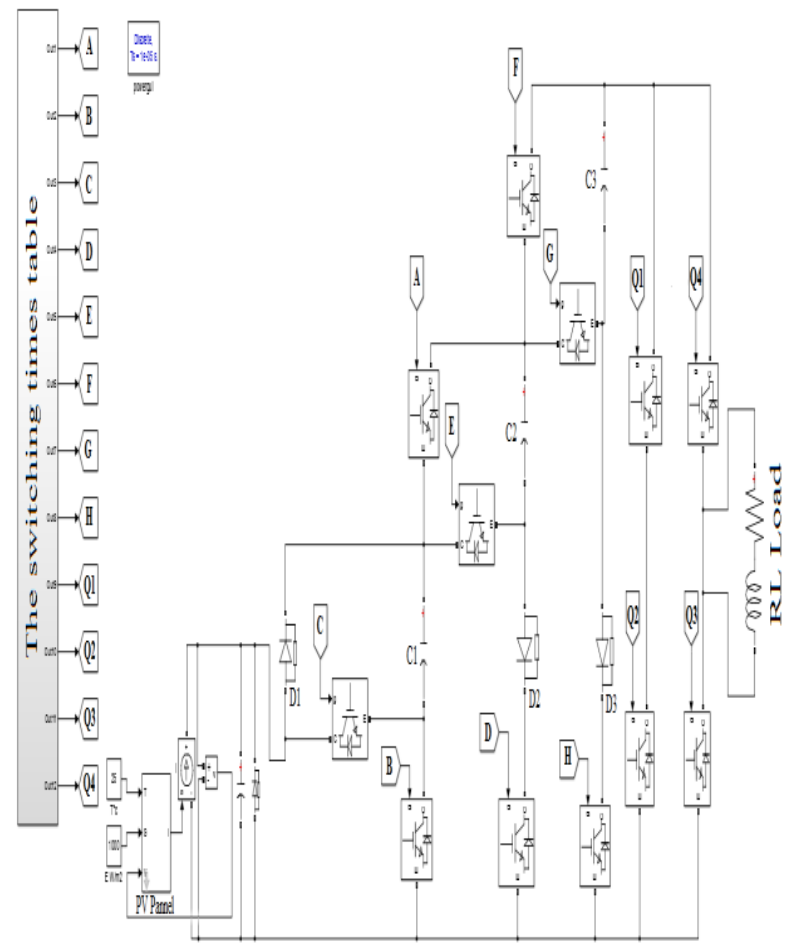

Fig 8.SIMULINK model of the studied system
Figure 9 shows the input voltage (Vin) and Figure 10 shows the input current (Iin) from solar panels.
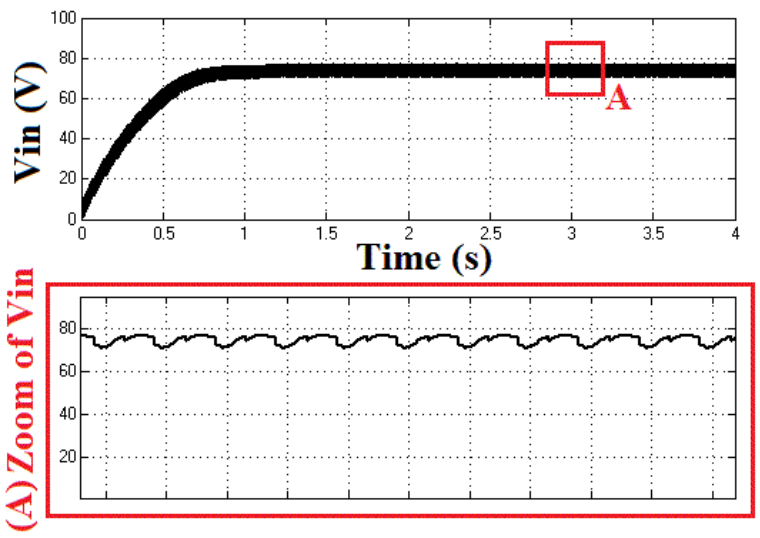

Fig 9.The input voltage from solar panels

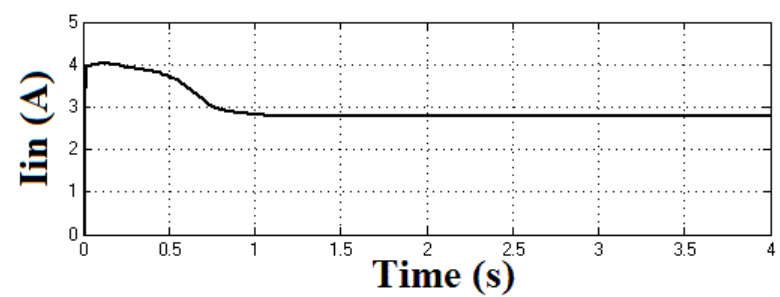

Fig 10.The input current from solar panels

From Figures 9 and 10, it's clear that the studied multilevel inverter can be easily tied with solar panels.

The average value of the input voltage is $75 \mathrm{~V}$ and the average value of the input current is $2.7 \mathrm{~A}$

The shape of the input voltage is due to the charging and discharging cycles of the used capacitors $(\mathrm{C} 1 ; \mathrm{C} 2$ and $\mathrm{C} 3)$.

The input voltage of $75 \mathrm{~V}$ is increased at $300 \mathrm{~V}$ by using the switched capacitor DC-DC converter. Figure 11 shows the output DC Bus voltage from this converter.

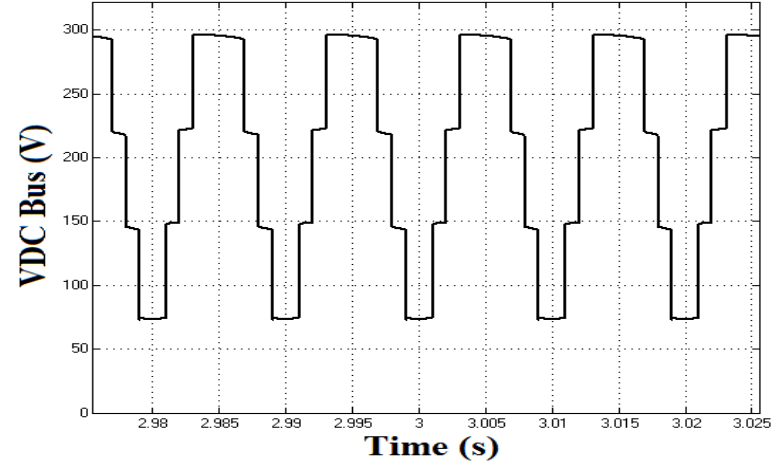

Fig 11.Output DC Bus voltage

From Figure 11, the DC-DC converter generates a positive staircase waveform that begins from $75 \mathrm{~V}$ and ends at $297 \mathrm{~V}$, repeated in this case at each half period $(0.01 \mathrm{~s})$; this justifies that the capacitors voltages are balanced.

This staircase voltage will be converted to an AC voltage, by using the full bridge converter.

Figures 12 and 13 show respectively the output AC voltage (VAC) and output AC current (IAC) from the studied multilevel inverter. 


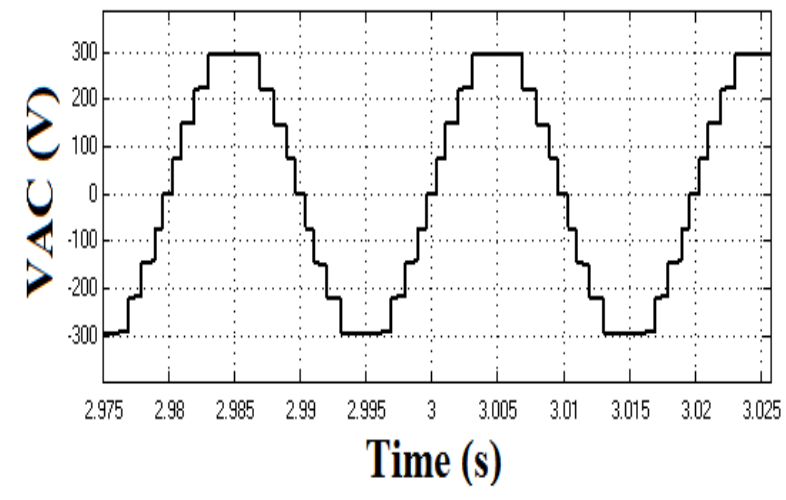

Fig 12.The output AC voltage

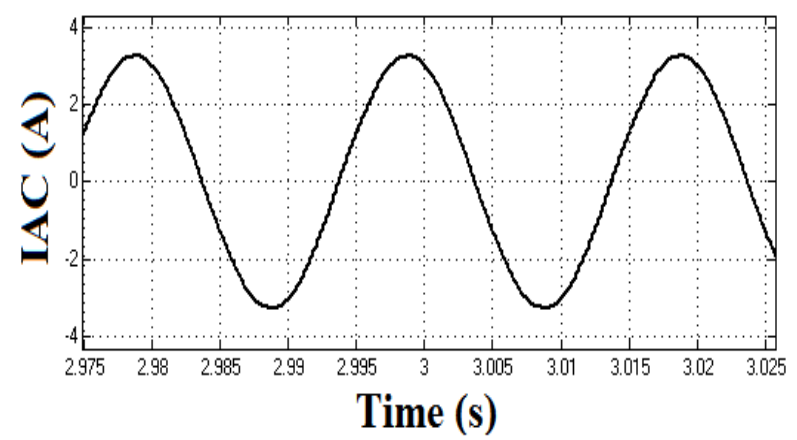

Fig 13.The output AC current

From Figures 12 and 13, the multilevel inverter delivers an AC voltage to the inductive load with 9 levels similar to a sinusoidal in shape without using a filter. The RMS value of this output $\mathrm{AC}$ voltage is about $220 \mathrm{~V}$ because the modulation index of the implemented control method is 1.05 . The output $\mathrm{AC}$ current is sinusoidal with an RMS value of $2.3 \mathrm{~A}$. The frequency is fixed at $50 \mathrm{~Hz}$.

Figure 14 shows the THD of the output AC voltage using the FFT toolbox.

\section{THD of VAC}

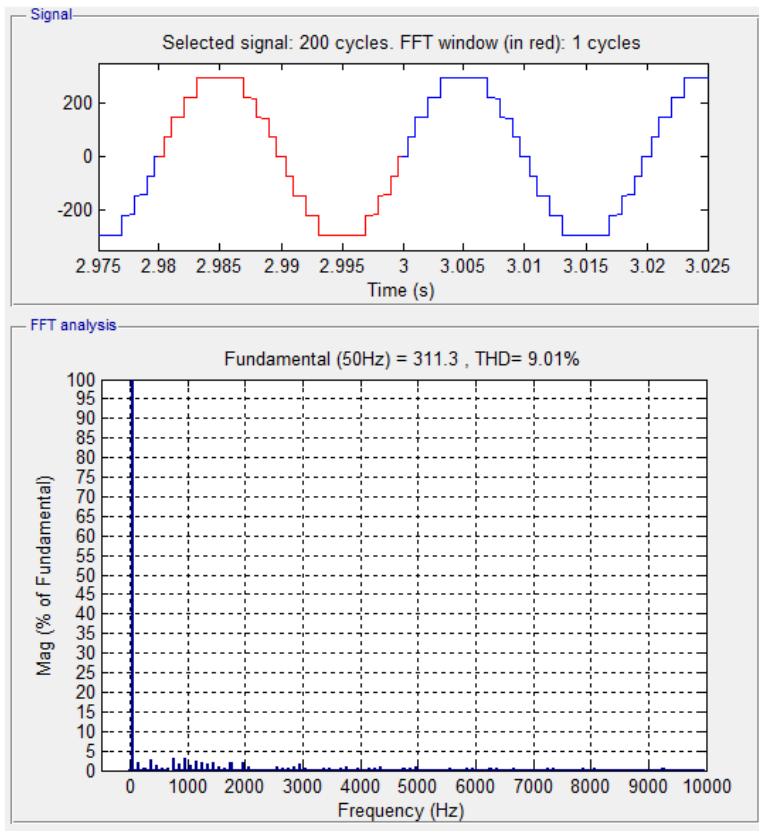

Fig 14. The computed THD of the output AC voltage
From Figure 14, the studied multilevel inverter delivers an AC voltage with fewer harmonics $(9.01 \%)$. This justifies the good functioning of the studied control method.

From all the results presented in this section, it's clear that this multilevel inverter is able to supply power energy to the inductive loads by delivering good output $\mathrm{AC}$ waveforms.

\section{EXPERIMENTAL RESULTS}

An experimental prototype of the studied multilevel inverter was fabricated at the laboratory and tested with $130 \mathrm{~W}$ single phase induction motor driving a water pump. The calculated switching times for the power MOSFETS with the selective harmonics method were implemented on a microcontroller. The experimental results were analyzed by using a digital oscilloscope with two channels for measuring; channel 1 (ch1) and channel 4 (ch4)

Figure 15 shows the experimental test bench with the single phase induction motor.

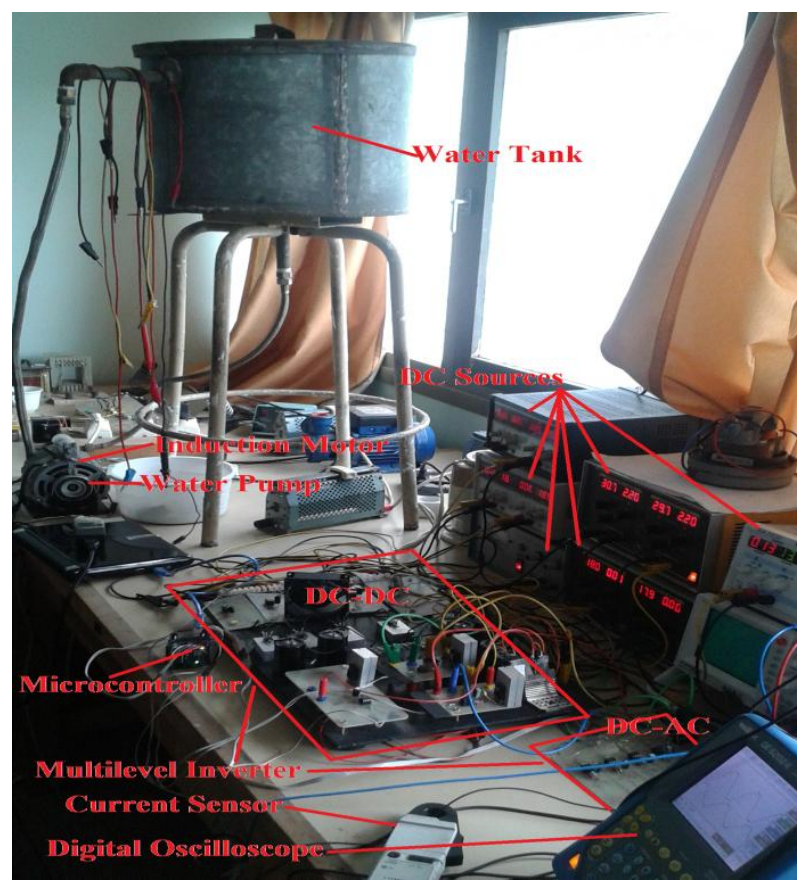

Fig 15.The experimental test bench

In this experimental test, the input voltage Vin for the pumping system was taken from stiff DC voltages. Figure 16 shows the average value and shape of this input voltage.

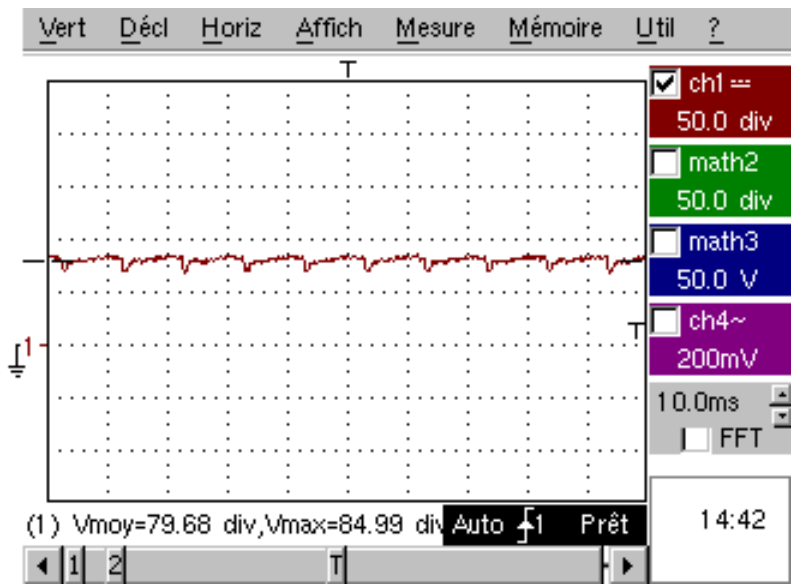

Fig 16.Input voltage Vin (ch1) for the pumping system 
From Figure 16, the DC sources deliver an average value of $79 \mathrm{~V}$ to the pumping system. The shape of this voltage is similar to the input voltage Vin obtained from solar panels in simulation results (see Figure 9); it's is due to the charging and discharging cycles of the used capacitors $(\mathrm{C} 1 ; \mathrm{C} 2$ and C3).

This input voltage will be increased by the fabricated DC-DC switched capacitor converter. Figure 17 shows the output DC Bus voltage from this DC-DC converter.

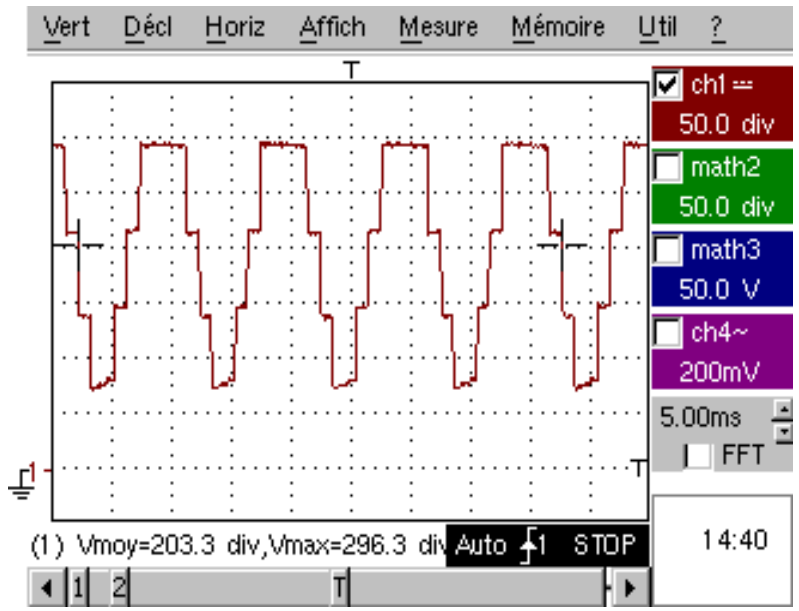

Fig 17.Practical output DC Bus voltage (ch1)

From Figure 17, the implemented DC-DC converter generates a positive staircase waveform, that begins from $79 \mathrm{~V}$ and ends at $296 \mathrm{~V}$ (ch1), repeated at each half period $(0.01 \mathrm{~s})$, the shape and value of this voltage are identical to simulation results (see Figure 11).

This staircase voltage will be converted to an AC voltage, by the implemented DC-AC converter which will drive the single phase induction motor.

The output $\mathrm{AC}$ voltage and the output $\mathrm{AC}$ current from the fabricated multilevel inverter are shown in Figure 18 and Figure 19.

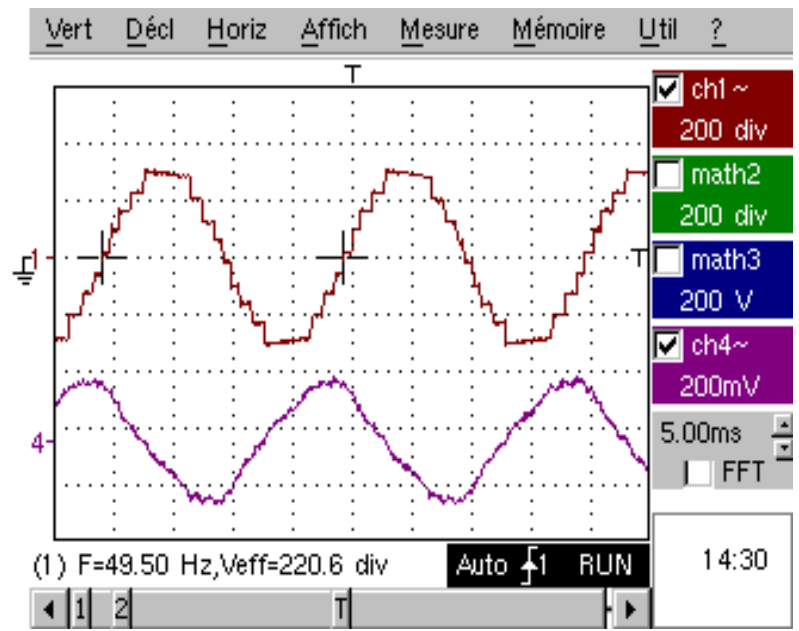

Fig 18.Output AC voltage (ch1) and output AC current (ch4)

From Figure 18, the implemented multilevel inverter delivers an output AC voltage with nine levels similar to a sinusoidal in shape and close to the simulation results (see Figure 12). The RMS value of this voltage is $220 \mathrm{~V}$ (ch1). The frequency is set to be $50 \mathrm{~Hz}$.

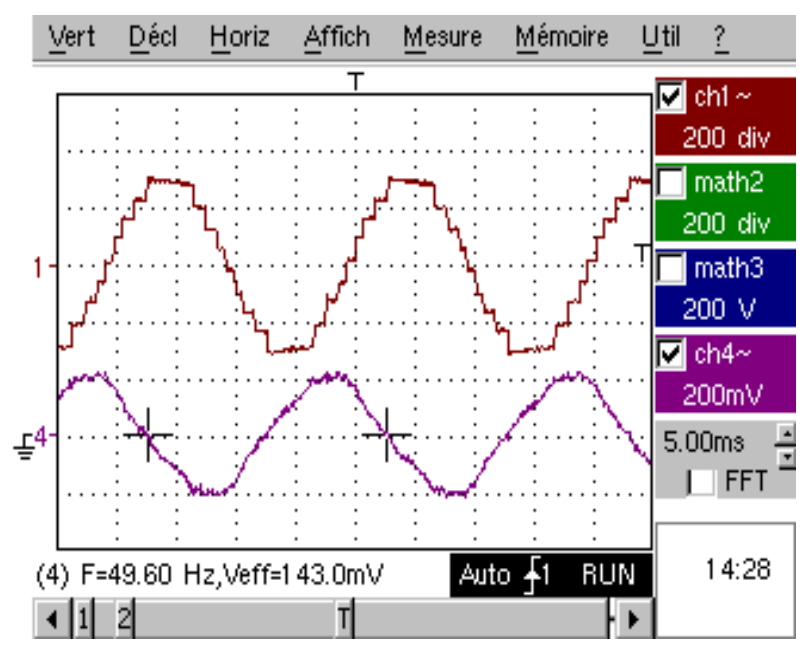

Fig 19.Output AC voltage (ch1) and output AC current (ch4)

From Figure 19, the output current is sinusoidal and close to the simulation results (see Figure 13). The RMS value of this current is $1.43 \mathrm{~A}$ (ch4) because the used current sensor delivers $100 \mathrm{mV}$ for each RMS value of $1 \mathrm{~A}$.

The harmonic spectrums of the output AC voltage and output AC current are shown in Figure 20 by using the FFT option available into the digital oscilloscope program.

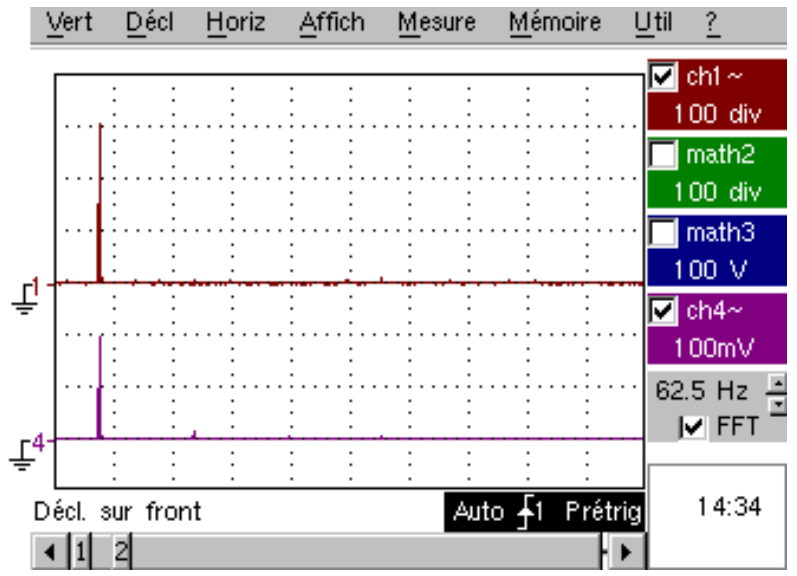

Fig 20. The harmonic spectrum of the output AC voltage (ch1) and output AC current (ch4)

From Figure 20, the implemented multilevel inverter delivers fewer harmonics. The experimental harmonic spectrum is close to the simulation results (see Figure 14); this proves that the implemented calculated switching times into the microcontroller are identical to those implemented on MATLAB/SIMULINK.

These experimental results demonstrate that the studied multilevel inverter is able to supply power energy to industrial machines, such as induction motors used for example in photovoltaic pumping systems.

\section{CONCLUSION}

In this paper, a test of an efficient multilevel inverter for photovoltaic systems was presented. The principal element of this inverter is a high step-up DC-DC converter which is apt to increase voltage from small DC voltage sources to high value without using inductors or high-frequency transformers just by switching capacitors in series and in parallel. 
The studied multilevel inverter generates an output AC voltage with 9-levels by using a single dc voltage as input DC source.

The implemented control method in this study is very simple and helps the studied system to delivers good output AC waveforms similar to a sinusoidal in shape with fewer harmonics ( $9 \%$ for the AC voltage) without using filters.

The fabricated laboratory prototype of this inverter has been tested with standard values of voltage (220V RMS) and frequency $(50 \mathrm{~Hz})$.

The simulation results of the studied inverter with modeled solar panels are identical to the experimental results with regulated power supply.

This multilevel inverter provides a better operation for electrical machines used in PV system applications such as induction motors.

In a future work, a closed loop control system with a maximum power point tracking (MPPT) algorithm will be implemented and will be tested on the studied PV system.

\section{REFERENCES}

[1] M. Malinowski, J. I. Leon, and H. Abu-Rub, "Solar Photovoltaic and Thermal Energy Systems: Current Technology and Future Trends," Proceedings of the IEEE, vol. PP, no. 99, pp. 1-15, 2017.

[2] X. Liang, "Emerging Power Quality Challenges Due to Integration of Renewable Energy Sources," IEEE Transactions on Industry Applications, vol. 53, no. 2, pp. 855-866, Mar. 2017.

[3] R. A. Krishna and L. P. Suresh, "A brief review on multi level inverter topologies," in 2016 International Conference on Circuit, Power and Computing Technologies (ICCPCT), 2016, pp. 1-6.

[4] K. K. Gupta, A. Ranjan, P. Bhatnagar, L. K. Sahu, and S. Jain, "Multilevel Inverter Topologies With Reduced Device Count: A Review," IEEE Transactions on Power Electronics, vol. 31, no. 1, pp. 135-151, Jan. 2016.

[5] A. Nouaiti, A. Saad, M. Khafallah, A. Mesbahi, and K. Chikh, "Simple Single Phase Five Level Inverter for PV Applications," IJAREEIE, vol. 4, no. 6, 2015.

[6] S. H. Shehadeh, H. H. Aly, and M. E. El-Hawary, "Photovoltaic multi-level inverters technology," in 2015 IEEE 28th Canadian Conference on Electrical and Computer Engineering (CCECE), 2015, pp. 648-655.
[7] Y. Ye, K. W. E. Cheng, J. Liu, and K. Ding, “A Step-Up Switched-Capacitor Multilevel Inverter With SelfVoltage Balancing," IEEE Transactions on Industrial Electronics, vol. 61, no. 12, pp. 6672-6680, Dec. 2014.

[8] Y. Hinago and H. Koizumi, "A Switched-Capacitor Inverter Using Series/Parallel Conversion With Inductive Load," IEEE Transactions on Industrial Electronics, vol 59, no. 2, pp. 878-887, Feb. 2012.

[9] Y. Hinago and H. Koizumi, "A modulation method for capacitor voltage ripple reduction of the switchedcapacitor inverter using series/parallel conversion," in 2011 IEEE International Conference on Industrial Technology, 2011, pp. 105-109.

[10] A. Tsunoda, Y. Hinago, and H. Koizumi, "Level- and Phase-Shifted PWM for Seven-Level SwitchedCapacitor Inverter Using Series/Parallel Conversion," IEEE Transactions on Industrial Electronics, vol. 61, no. 8, pp. 4011-4021, Aug. 2014.

[11] A. M. A. Al-Janabi and E. T. Hashim, "Modeling of PV Module Performance under Influence of Surrounding and Essential Factors Variation using Matlab Simulink," International Journal of Computer Applications, vol. 130, no. 3, pp. 40-44, 2015

[12] K. Ding, X. Bian, H. Liu, and T. Peng, "A MATLABSimulink-Based PV Module Model and Its Application Under Conditions of Nonuniform Irradiance," IEEE Transactions on Energy Conversion, vol. 27, no. 4, pp. 864-872, Dec. 2012

[13] R. Barzegarkhoo, H. M. Kojabadi, E. Zamiry, N Vosoughi, and L. Chang, "Generalized Structure for a Single Phase Switched-Capacitor Multilevel Inverter Using a New Multiple DC Link Producer With Reduced Number of Switches," IEEE Transactions on Power Electronics, vol. 31, no. 8, pp. 5604-5617, Aug. 2016.

[14] E. Zamiri, N. Vosoughi, S. H. Hosseini, R. Barzegarkhoo, and M. Sabahi, "A New Cascaded Switched-Capacitor Multilevel Inverter Based on Improved Series-Parallel Conversion With Less Number of Components" IEEE Transactions on Industrial Electronics, vol. 63, no. 6, pp. 3582-3594, Jun. 2016.

[15] Wahidah Abd. Halim, Nasrudin Abd. Rahim, and Maaspaliza Azri, "Selective Harmonic Elimination for a Single-Phase 13-level TCHB Based Cascaded Multilevel Inverter Using FPGA," Journal of Power Electronics, Vol. 14, no. 3, pp. 488-498, May. 2014. 